\title{
SESIÓN NECROLÓGICA EN MEMORIA DEL PROF. FRANCISCO ALONSO FERNÁNDEZ
}

\author{
Manuel Díaz-Rubio García \\ Académico de Número de la Real Academia Nacional de Medicina de España-Medicina Interna
}

Excmo. Sr. Presidente de la Real Academia Nacional de Medicina de España, Excmo. Sr. Secretario General, Excmos. e Ilmos. Sras. y Sres. Académicos, Familia del profesor Alonso Fernández, señoras y señores.

La Junta Directiva de la Real Academia Nacional de Medicina de España me ha designado para realizar el discurso necrológico del Excmo. Sr. Dr. D. Francisco Alonso Fernández fallecido el 28 de junio de 2020. Un honor, impregnado de tristeza, por cuanto supone para la Institución su pérdida. Ese sillón número 16, que tantos años ocupó, se nos muestra hoy como un enorme vacío que se nos antoja difícil de llenar. La Academia tiene el compromiso y la obligación moral ineludible de recodar a los que nos precedieron, así como dejar constancia de su personalidad y labor. El profesor Alonso Fernández, personalidad absolutamente libre e independiente, destacó sobremanera como un gran pensador, dotado de una extraordinaria capacidad analítica, grandes conocimientos, dejando un gran legado por la originalidad de sus aportaciones. El 5 de junio de 1979 ingresó con el discurso Bases psicosociales del alcoholismo, que ya por entonces impactó profundamente por su contenido científico, su visión del problema, y las propuestas innovadoras que planteó. Debo señalar que en el momento de su fallecimiento era el Académico de número más antiguo.

Existen a mi juicio tres momentos trascendentes en la vida académica en relación con sus miembros. El primero, un acto de gran responsabilidad, es aquél en el que los señores académicos se comprometen con su conciencia, honor y la institución al depositar su voto para elegir a un nuevo miembro. De alguna forma se están eligiendo así mismo, de ahí la importancia de este momento en que cada uno de nosotros nos juzgamos. Un segundo momento crucial es aquél en que el académico elegido toma posesión de su sillón, lee su discurso de ingreso y se compromete con la Institución. Un compromiso que pesa sobre nosotros el resto de nuestra vida. El tercero, lleno de dolor, es la sesión necrológica en la que la Real Academia rinde homenaje tras su fallecimiento a un académico, dándole entrada en la historia de la Academia y de la medicina española y universal.
Todavía resuena en mis oídos la llamada que el profesor Alonso me hizo tan solo tres días antes de fallecer en la que me pidió determinadas cosas y en la que me dijo con voz firme, llena de pena: "Manolo, me voy ya". Conociendo su estado de salud sabía que quería decir, aunque para bajar le tensión del momento le dije en tono distendido: " ¿Y... donde vas a ir? Ya queda muy poco para que hagas la presentación de tu libro sobre Felipe $V$ y hay una gran expectación". Guardó silencio y quedamos en hablar al siguiente día, en el que le dije que le llevaría las papeletas para las votaciones a cargos de la Junta Directiva y una plaza de Académico, que se iban a celebrar. No quería, y en ello insistía, que cuando se le llamara para depositar su voto se oyera una voz que dijera: "Alonso Fernández, no vota". Para él cumplir con las obligaciones académicas era algo que había voluntariamente aceptado hacía más de 40 años y no estaba dispuesto a fallar.

Debemos considerar a Alonso Fernández como uno de los intelectuales y científicos más importantes de la psiquiatría española del siglo XX y lo que llevamos vivido del siglo XXI. Su obra, sin duda altamente innovadora, ha sido de gran relevancia y una referencia inagotable para sus contemporáneos y las nuevas generaciones. No pasa a la historia solo como un eminente psiquiatra clínico, que también, sino alguien que ha puesto en marcha y demostrado en su especialidad, nuevas formas de entender el pensamiento y ofreciendo su disciplina a profundos cambios en el mejor entendimiento de la enfermedad y los aconteceres de cuantos las padecen. Gracias a sus propuestas transformadoras y vastos estudios, hoy es posible comprender conductas, circunstancias y hechos que, previas investigaciones, nunca habían conseguido.

Federico II el Grande gran defensor de las Academias, decía: «conocimientos pueden tenerlos cualquiera, pero el arte de pensar es el regalo más escaso de la naturaleza». Y en esto del pensar, queridos académicos, el profesor Francisco Alonso Fernández era un gran maestro. Un ejemplo de lo supone ir mas allá de la mera interrelación con el paciente.

En su libro Genios y creativos habla de las tres clases del talento extraordinario, refiriéndose al sabio como aquél que rebosa conocimientos extraordinarios, al superdotado por su riqueza en

\section{Autor para la correspondencia}


la inteligencia fluida, y al genio por su caudal en la capacidad creativa. Un día, hablando de este libro, le pregunté que en que grupo se incluiría él. Me miró sonriendo y me dijo: "Tú... cómo me ves? No me dejó contestarle y con gran elegancia cambió la conversación. Yo diría, y le conocía bien, que sin señalar ninguno de tales atributos el profesor Alonso Fernández rezumaba conocimientos no al alcance de cualquiera, tenía una gran inteligencia y su capacidad creativa era enorme. Lo tenía pues todo: sabiduría, inteligencia y genialidad. Saquen ustedes las conclusiones.

Me gusta repetir, como he dejado constancia en mis libros sobre Médicos Españoles de siglo XX y esta Real Academia, que para pasar a la historia de la medicina se deben dar determinadas condiciones como, la relevancia de los puestos de responsabilidad que desempeñó en el ámbito de la medicina y la universidad, su aportación científica, la obra escrita, la formación de escuela, haber destacado sobremanera en su especialidad, así como el reconocimiento de la comunidad científica y de la sociedad en general. No cabe duda de que, en el caso de Francisco Alonso Fernández, todas estas condiciones están presentes, por lo que se trata de alguien que pasará con letras de oro a la historia de nuestra medicina.

El profesor Francisco Alonso Fernández nació en Oviedo el 13 de febrero de 1924. Su padre, Crisanto Alonso Pérez, al que nunca pudo olvidar por cuanto significó en su vida, fue concejal del Ayuntamiento de Oviedo entre 1931 y 1936, afiliado a Izquierda Republicana, miembro de la masonería, implacablemente perseguido tras la Guerra Civil. Al comienzo de ésta un veraneo en Colombres le salvó la vida, al no encontrarle los insurrectos ni en su vivienda en Oviedo ni otros lugares. De ello no pudo librarse su hermano mayor, que fue fusilado. Tras la guerra, desposeído de todos sus bienes y un tiempo en la cárcel, permaneció oculto en Madrid haciéndose pasar por tío carnal de nuestro admirado académico, conviviendo como compañeros de habitación en diferentes pensiones familiares durante sus estudios de medicina en la vieja Facultad de Medicina de Atocha. Todos estos hechos, vividos en primera persona, dejaron sin duda una profunda huella en su vida, pero en modo alguno le llevaron por al camino del resentimiento y la venganza. Tras el fallecimiento de su padre en 1954 optó, tras un proceso de reflexión, por la discreción y el "silencio político".

Francisco Alonso Fernández realizó sus estudios primarios en el Colegio de los Maristas de Oviedo, posteriormente pasó al Instituto Jovellanos y completó el bachillerato en la Academia Politécnica y en la Academia Hispania de Oviedo. Inició la carrera de Medicina en Madrid en 1941, terminándola en la de Salamanca a donde marchó para estar cerca de la que sería la mujer de su vida, Mary, Ma Dolores San Martín. Siempre recordaba que su vocación por la medicina partió, desde su juventud, por el comportamiento ejemplar de los médicos, bien fueran de unas ideas o de otras.
En su vocación por la psiquiatría influyó, además de su visión antropológica, el haber asistido algunas temporadas a un sanatorio psiquiátrico en Oviedo que dirigía un tío carnal suyo. En 1948, recién acabada la carrera comenzó a trabajar como médico de guardia en el Hospital Psiquiátrico La Cadellada en Oviedo. Sin embargo, deseoso de saber más y formarse mejor se trasladó a Madrid, primero a la cátedra de Vallejo Nájera, la cual pronto abandona tras ser testigo de un discurso excluyente, incorporándose a la de Juan José López Ibor. En ella trabajó junto a Bartolomé Llopis, al cual pronto le unió no solo su sabiduría científica, sino una ideología social y liberal más cercana a su pensamiento.

Sin embargo, esta decisión de formarse en Madrid pronto se interrumpió al ser nombrado en 1949, por concurso-oposición nacional, Jefe de los Servicios Provinciales de Higiene Mental y Toxicomanías del Instituto Provincial de Sanidad de La Coruña. Allí comenzó a desarrollar todo su potencial creando estructuras modernas, como un club de socioterapia, y prestando una muy especial atención a la psiquiatría social. Ahí inició sus estudios sobre el alcoholismo, con tal pasión y sumergiéndose tanto en los problemas derivados de esta adicción que algunos pacientes le preguntaban si él también era alcohólico.

\section{La Universidad. La Cátedra.}

Su vida universitaria comenzó al ser nombrado profesor ayudante de clases prácticas en 1955 en la Cátedra de Farmacología en Santiago de Compostela. Este nombramiento era para él capital, pues le permitía tras tres años de docencia poder presentarse a oposiciones a cátedra, su gran ilusión. Para completar su formación en 1959 trabajó junto a Manfred Bleuler, en la Psychiatrische Universitätklinik en Zurich y ese mismo año leyó su tesis doctoral, Alteraciones psíquicas y neurológicas en la intoxicación por manganeso, dirigida por Juan José López Ibor.

En 1969, tras diversos avatares no exentos de cierto cariz político, accedió a la Cátedra de Psiquiatría de la Universidad de Sevilla, la primera en la historia de esa Universidad. Encargado además de la asignatura de Psicología, su labor en la cátedra fue asombrosa, creando estructuras hasta entonces desconocidas, destacando entre otras la creación de la Escuela Profesional de Psiquiatría (1970), la especialidad de Psiquiatría en la Escuela de Ayudantes Técnicos Sanitarios (1971), la Escuela de Piscología para Asistentes Sociales (1974) y la Cátedra de Psiquiatría Infantil (1975). Además, durante su estancia en Sevilla impartió multitud de cursos monográficos del doctorado y otros abiertos, así con congresos y diversas reuniones con especialistas.

Aunque feliz en Sevilla, y lleno de dudas en cuanto a sus opciones, en 1974 optó a la cátedra de Psiquiatría de la Facultad de Medicina de la Universidad Complutense de Madrid. Con apenas cumplidos los 50 años, tanto prestigio y un largo recorrido 
por delante en su reto universitario, no tenía otro camino. Sabía de las dificultades, de no ser bien acogido por algunos de los más influyentes en esos momentos, pero las dificultades nunca fueron un obstáculo para sus retos e ilusiones. Hasta 1977 no tuvo lugar la resolución del concurso que ganó sin lugar a discusión. Tenía veinte años por delante para seguir con sus objetivos universitarios. Sin embargo, en el año 1984 a instancias del Gobierno de la Nación se aprobó en el Parlamento y publicó en el BOE la Ley de Medidas para la Reforma de la Función Pública que obligaba a la jubilación a los 65 años de todos los funcionarios sin distingo a la condición docente.

Un palo para el profesor Alonso Fernández y el estamento universitario. Esa calculada ley de jubilación anticipada, para regocijo de muchos y la tristeza de los mejores, destrozó la universidad y acabó con una generación de intelectuales del máximo nivel en este país. La Real Academia debería en algún momento analizar las hondas repercusiones que en todos los órdenes tuvo esta iniciativa gubernamental.

Cuando ello ocurre el profesor Alonso ya había trasformado la Cátedra y el Servicio de Psiquiatría del Hospital Clínico de San Carlos, dejando constancia de su nueva forma de entender la psiquiatría y el manejo de los pacientes psiquiátricos. Que tuvo dificultades y obstrucciones a su forma de concebir la especialidad no fue nada nuevo en la historia de la Universidad. Su irrupción en la Cátedra y Servicio fue como un gran terremoto que no todos sus miembros veían con buenos ojos, ya que sus objetivos de cambio chocaban con sus ideas conceptuales de la psiquiatría que no eran compartidas ni asumidas por ellos. En este sentido siempre recordó el gran apoyo que tuvo del profesor adjunto Carlos Carbonell, académico correspondiente de esta Real Academia, gran psiquiatra y hombre excepcional.

El profesor Alonso Fernández hablaba de cambios importantes no solo en la organización psiquiátrica sino en la profundización en la psiquiatría social, la importancia de la transhistoria, los nuevos modelos clasificatorios de las depresiones, la comprensión y manejo de las adicciones, la salud mental, o la profundización en la enfermedad y el hombre libre, entre otros objetivos.

Dentro de los muchos cambios que realizó en la organización de la Cátedra y Servicio quedan para la historia la independización del hospital de día de la hospitalización, la modificación de la atención de las urgencias psiquiátricas y la revisión de los tratamientos mecánicos de sujeción, así como un cambio profundo en las largas hospitalizaciones. Estas tres metas pronto las vio cumplidas no sin ciertas dificultades.

A pesar de que sus éxitos y reconocimientos fueron enormes, le quedaron algunos sinsabores que siempre recordó. El primero fue la falta de colaboración de algunos de los más destacados miembros de la Cátedra y Servicio, que suplió con la absoluta implicación de gente joven llena de ilusión. El segundo de ellos fue la desaparición de la Escuela Profesional de Psiquiatría y su sustitución por el sistema MIR. El MIR le parecía bien pero no entendía la supresión de las Escuelas que tanto prestigio daba a la Psiquiatría española en el mundo latinoamericano, si bien reconocía que posiblemente no era igual en otras especialidades. Un tercer sinsabor fue el no haber podido completar la unidad de tratamiento de las adicciones que trató de montar. Problemas internos, de índole muy diversa, fundamentalmente con la metadona le llevaron tras un largo tiempo de lucha al abandono de dicho proyecto, más por imposición superior que por voluntad propia.

El cuarto sinsabor fue la jubilación en 1990, a los 65 años. Pero..., esta jubilación no acabó con él como en otros muchos casos, sino que siguió trabajando con enorme intensidad. Ya no tenía el poder de la Cátedra ni del Servicio, pero sí el de la libertad, tal como la entendía, y ello le permitió abordar nuevos proyectos, siempre de carácter innovador. Tras esa injusta jubilación aún vivió 31 años, en los que cada uno de ellos fue testigo de nuevas e innovadoras aportaciones.

\section{Su obra}

Tarea imposible, inabordable, es querer por mi parte, en esta sesión necrológica, condensar su extensa, profunda e innovadora obra y su repercusión en la vida universitaria, científica y académica.

La obra de Alonso Fernández no es una sucesión de acciones y publicaciones desconexas. Se trata de la consecución de un objetivo que gira alrededor de la libertad dando a cada acción o publicación un claro sentido. Su idea del hombre libre le lleva a introducirse en el hombre enfermo, precisamente para que recupere su libertad.

Es difícil entender la aportación de Alonso Fernández sin sumergirse en los momentos y vivencias que le tocó vivir, desde la vertiente personal con experiencias terribles, hasta la Guerra Civil española y la II Guerra Mundial. Vio y vivió lo que era la pérdida de la libertad en el ser humano y atisbó en la medicina un gran campo para profundizar en ella y devolver al paciente la autonomía perdida. Él mismo dejó escrito, como estímulo para su vocación, que "Entre los escasos rasgos positivos compartidos por ambos costados bélicos se inscribe con letras de oro la acerada profesionalidad y profundo sentido humanitario presentes en la conducta de los médicos republicanos $y$ nacionales".

Pero además surgió en él un problema, que trató de solucionar sin éxito, como fue la búsqueda de mejorar su formación al lado de los más reputados maestros. Tras su decepción, en Madrid, con Vallejo Nájera, como ha sido comentado, por disidencias importantes entre ambos, y el vacío de los 
miembros de la escuela de López Ibor tras ser muy bien acogido por este, volvió a La Coruña donde a base de trabajo, estudio, asistencias a congresos, contactos con psiquiatras españoles y extranjeros, y exponiendo a todos ellos sus pensamientos logró una formación realmente impresionante, siempre, como él decía e insistía hasta la saciedad, de una forma independiente y bajo su sola responsabilidad. Esa independencia, libre de las ataduras de pertenencia a una escuela determinada, le permitió desarrollar prontamente su visión de la rama del saber motivo de su vocación. El objetivo: el hombre libre en toda su extensión.

Su formación y aportación a la psiquiatría se pone prontamente de manifiesto asombrando a todos con la publicación en 1968 del libro Fundamentos de la Psiquiatría actual, en dos volúmenes de dos mil páginas escrito en solitario, viendo la luz años después, en 1974, su obra Psicología médica y social, habiendo alcanzado ambas las cinco ediciones. El prólogo de su libro de psiquiatría realizado por el profesor López Ibor contiene grandes elogios destacado el gran esfuerzo realizado, actualidad, claridad y la realidad psiquiátrica de ese momento. Es de gran interés señalar que, partiendo de la antropología médica, desarrolló su concepto en el sentido de que la psicopatología general y la psiquiatría clínica era un todo continuo de la misma forma que ocurre en medicina interna con la patología general y la patología médica.

Su aportación a la psiquiatría y psicología, sin separar una de otra, ha sido intensa y de calado. Su pensamiento doctrinal se decantó prontamente por la psiquiatría social y clínica, y es aquí donde su figura emerge aportando una nueva luz y enfoque de muchos de los trastornos psiquiátricos. Aunque resulta difícil de sintetizar en el poco tiempo de que disponemos en esta sesión, cabe resaltar su monumental quehacer en todo lo referente a la psiquiatría social. Para él, el paciente lo era todo siempre en la búsqueda de liberarlo de sus ataduras y recuperar la libertad. Defendía la psiquiatría participativa, de la cual era un defensor, basándose en que el paciente no es ajeno a su participación en el proceso asistencial, mejorando de esa forma el cumplimiento y respuesta terapéutica. Puede decirse, sin temor a equivocarnos, que sus trabajos y propuestas marcan un antes y después de la psiquiatría en España. La creación del equipo psiquiátricosocial con visitadoras sociales en 1952 y la puesta en marcha del Club de Socioterapia, ya en 1962, significaron un rumbo tan importante y rupturista con enfoques anteriores, que le llevaría a convertirse a nivel nacional e internacional en un auténtico líder en lo referente a la Psiquiatría Social.

A un lado sus aportaciones conceptuales y clínicas a la psiquiatría, su obra se extiende más allá de ello y de la publicación de sus dos tratados de psiquiatría y psicología. Repasaremos, aunque sea de forma sucinta, algunas de sus más importantes contribuciones que dividiremos de una forma artificial en cuatro apartados: 1) los estados depresivos, 2) el alcoholismo y otras adicciones, 3) la psicohistoria, y 4) la transhistoria.
El estado depresivo fue desde sus inicios como psiquiatra un área de especial interés para él. Apoyándose en la transhistoria, en los cambios sociales y valorando el impacto de los hechos dramáticos que le había tocado vivir, no solo a él sino a todos los españoles durante la guerra civil, llega a la conclusión de que las formas de expresarse la enfermedad son cambiantes y de alguna forma se adaptan a vivencias culturales. En este sentido, el entorno, tan importante para él en su concepto de la libertad y el hombre libre, toma un impulso preponderante.

Publicaciones importantes que muestran su preocupación por estos estados son sus decenas de artículos en revistas nacionales e internacionales y sus libros, entre otros: Formas actuales de la depresión (1981), Síndrome depresivo (1984), La depresión y su diagnóstico. Nuevo modelo clínico (1988), Vencer la depresión con la ayuda del médico, la familia y los amigos (1994), Claves de la depresión (2001), el Manual de Cuestionario Estructural Tetradimensional para el diagnostico y clasificación de la depresión (1986) y Las cuatro dimensiones del estado depresivo (2009).

Una aportación singular y trascendente fue su modelo depresivo tetradimensional, el cual establece sobre cuatro pilares: el estado de ánimo depresivo, la anergia o vaciamiento del impulso afectivo, la discomunicación y la disregulación de los ritmos. El derrumbamiento de cualquiera de estos estos pilares, intercomunicados, se extendería a los demás, dando lugar al caos de la enfermedad. Crítico con el catálogo DSM, completó su pensamiento con la estructuración original de un cuestionario tetradimensional para la valoración de la depresión, capaz de distinguir hasta 15 tipos semiológicos diferentes. Este cuestionario, que patentó, originó múltiples publicaciones tanto por su parte, sus discípulos, como gran cantidad de psiquiatras de todo el mundo, además de ser motivo de diversas tesis doctorales, entre otras la de su hija Covadonga, Académica correspondiente de esta Real Academia..

Sus estudios y contribuciones sobre el alcoholismo le llevaron a liderar multitud de iniciativas tanto nacionales como internacionales. Tras publicar en 1969 un artículo sobre los factores socioculturales del alcoholismo acometió un Estudio epidemiológico del alcoholismo en España que dio lugar a un libro que apareció en 1966. Desde entonces sus trabajos en este campo fueron extensos destacando, además de sus artículos en revistas, sus libros Índice bibliográfico español del alcoholismo (1972), Bases psicosociales del alcoholismo (1979, Alcoholdependencia (1981), La personalidad del alcohólico (1988), y Los secretos del alcoholismo (1998). En todos ellos dejó su marca sobre la personalidad del dependiente, su pérdida de libertad, subrayando como el individuo afectado vive en un mundo marcado por el secreto, la trampa y la mentira. Se ocupó activamente de investigar sobre las causas y el tratamiento, preconizando en este sentido además de la terapia farmacológica la introducción previa de psicoterapia individual breve. 
Queda en su haber su dedicación y llamada de atención sobre otras dependencias, y entre ellas no solo a determinadas drogas como la heroína y su equivalente terapéutico metadona, sino otras de tipo social y no solamente químicas. Con respecto a las nuevas adiciones sociales, todas ellas legales como insiste, alimento, televisión, compras, juego, sexo y trabajo, fruto a su juicio del vacío, el aburrimiento, el estrés y la falta inmediata de gratificación, surge lo que denominó como "civilización adicta". Sobre estos aspectos hemos tenido la suerte de escucharle en la Academia en más de una ocasión. Fruto de su dedicación a estas nuevas adiciones son de destacar sus libros Las otras drogas (1996) y ¿Por qué trabajamos?: El trabajo, entre el estrés y la felicidad (2008), además de multitud de publicaciones.

Un grupo de estudios de alto interés, no solo por su profundidad sino por su continuidad, son los referidos al campo de psicohistoria. En él, el profesor Alonso aborda el estudio psicobiográfico de diversos personajes históricos aportando una visión muy diferente del impacto conocido de un determinado personaje en un momento histórico. Se trata de una ciencia nueva a la que él da entidad en España y extiende a otros muchos países. Alejado de los historiadores y sus propósitos, trata de ofrecerles una mejor comprensión de los hechos ocurridos a través del estudio de la personalidad y características psicológicas, incluso psiquiátricas en su caso. No trata de cambiar la historia, sino comprenderla mejor en función de la historia personal de aquellos personajes que estudia.

Su producción en este campo fue también extensa y de gran entidad, destacando sus obras Manual de Psicohistoria: Historia personal de los protagonistas de la historia (2014) en los que analiza el perfil psicológico o psiquiátrico, de personajes como Beethoven, Chopin, Padre Feijoo, Juana "La Loca" Carlos V, Felipe II, Felipe V, Goya, Kafka, Larra, San Juan de la Cruz, Hemingway, Don Quijote, Santa Teresa y Ramón y Cajal. Otros libros por resaltar son Historia personal de los Austrias españoles (2000), Perfil personal de don Santiago Ramón y Cajal (2006), El Quijote y su laberinto vital (2005), Don Quijote, el poder del delirio (2015), Historia personal de la monja Teresa de Jesús (2013), El enigma de Goya: la personalidad de Goya y su pintura tenebrosa (1999 y 2005). Algunos de estos estudios los encuadró dentro de lo que llamó psicomística, como el de Santa Teresa y Vivencias del estigmatizado religioso, psicoliteratura, como los de Don Quijote o Don Juan Tenorio, o psicoarte, como los de Goya.

Su último libro en el que tenía una gran ilusión y que no llegó a ver, aunque sí las galeradas, fue Felipe V. El Rey fantasma (2020). La pandemia del coronavirus le cerró las puertas a poder presentarlo, como era su intención, en la Feria del Libro de 2020, doblemente suspendida.

Especial importancia dio el profesor Alonso a la transhistoria, la cual estuvo presente a lo largo de toda su vida, insistiendo en la importancia de este concepto para una mejor comprensión de las enfermedades. A través de ella ayuda a comprender los cambios que se van produciendo en los avances científicos. Algunas de sus publicaciones, en forma de libros o artículos, en este campo tienen lugar desde su época más temprana, destacando entre otro muchos El hombre neurótico de hoy (1962), La metamorfosis histórica de la patología psiquiátrica en el marco de la sociedad actual (1968), Aspectos transhistóricos de las distintas modalidades de depresión (1972), El ocaso de la histeria determinado por la trasformación del ser humano, La violencia de género entendida como síndrome de Otelo (2017).

La producción científica del profesor Alonso queda recogida en sus 55 libros y 495 artículos en revistas, muchos de ellos en alemán, italiano, inglés o portugués. Fue además el Director de la Enciclopedia de Psicología y Pedagogía (1981) en su versión española y fundador y director durante 27 años la Revista de Psicología. Una profundización, aunque incompleta, de su obra puede ser acometida tras embeberse el número especial de la revista Anthropos que dedicó a su persona como homenaje en el año 2002.

\section{Su vida académica}

La vida académica del profesor Alonso Fernández ha sido plena. Su vinculación con la Real Academia Nacional de Medicina de España data de 1961 en que recibió el prestigioso Premio Pedro María Rubio. En 1964 fue nombrado Académico correspondiente y en 1979 ingresó como Académico de número. Desde entonces su compromiso y trabajo en ella fue abrumador. Un total de 56 años entregado a la Academia y cumpliendo con sus obligaciones de forma ejemplar.

En todos esos años ha dictado 43 conferencias sobre temas muy diversos en los que estaba trabajando, ofreciendo siempre primicias y aportaciones relevantes. Es de todo punto imposible ex esbozar, una síntesis de ellas, pero si quizás escoger alguna entre tantas como muestra de su respeto y consideración a esta Real Academia.

El año 2003 nos sorprendió con una profunda conferencia titulada El hombre libre, que sería publicada posteriormente en nuestra revista Anales. La importancia de ella iba mucho más allá de su relación con la salud mental, objetivo básico en esta conferencia, dejando entrever su pensamiento sobre la libertad individual, la dificultad de conseguirla cuando uno se enfrenta a la razón, y cómo el objetivo de una vida pasa por disfrutar de ella en toda su extensión. En este ensayo diferencia claramente el hombre libre existencial del hombre libre social, profundizando en los cambios conceptuales que se han producido desde el punto de vista histórico. Palabras textuales suyas son: “... estamos inmersos en una fase historicocultural donde casi nadie se libra de estar sujeto a una rígida programación de la vida, acompañada del asedio de un sinfín de coacciones, intentos de manipulación, sobrecarga 
de estrés o distrés ocupacional y la influencia de falsos valores (disvalores y antivalores). Tales condiciones resultan poco propicias para que cada quien pueda gobernarse con autonomía". Y continúa: "Los enfermos esperan de nosotros en esta perspectiva que les ayudemos a recuperar la libertad personal y/o la capacidad física, sin vulnerar su autonomía".

Sin duda el estudio riguroso de aquella conferencia nos lleva a descubrir su pasión por la libertad, dejando claro en ella, y en el libro El hombre libre $y$ sus sombras (Antropología de la libertad. Los emancipados y los cautivos), que publicaría en 2006, un auténtico ensayo sobre esta condición tan fácil de presumir de ella y tan difícil de ejercer. En él considera sujetos emancipados "...al intelectual o al rebelde, al artista o al científico y al político moral en el sentido de Kant". "La autonomía personal nace y se desarrolla a la luz de la razón. Sin el concurso de una razón legitimada, la libertad se extingue como tal". En cuanto a los sujetos cautivos estudia perfiles muy diversos como los racistas militares o enmascarados, los violentos, los religiosos sectarios, los enfermos adictivos, o los desesperados de si mismo que, como insiste, han sido instrumentalizados para combatir la cultura de la vida. Finaliza espoleando a buscar la libertad sobre la base de quien se siente auténticamente hombre libre disfruta de lo que denomina una "felicidad oceánica". Para él, el hombre libre debe serlo en el plano existencial y social, dado a "cultivar la felicidad propia y ajena”. Resulta claro que para Alonso Fernández la libertad fue el eje de su vida, en una cultura en la que el odio a esta, a la inteligencia y la independencia forma parte del día a día. Lástima no disponer de más tiempo para profundizar en sus pensamientos sobre la libertad o mejor dicho el hombre libre.

Durante muchos años fue el Presidente de la Sección de Medicina Legal, Psiquiatría e Historia de la Medicina de nuestra Academia, académico correspondiente de la de Bellas Artes y de Medicina de Andalucía Oriental. En el año 2018 recibió el homenaje a la antigüedad académica por parte del Instituto de España con un magnífico y atinado discurso del académico Francisco González de Posada.

\section{Impacto en la Sociedad Científica y reconoci- mientos}

Su involucración en las sociedades científicas arranca prontamente, acudiendo a Congresos nacionales e internacionales presentando diferentes comunicaciones. El arranque de responsabilidades comienza en 1961 en fue nombrado Secretario de la Comisión Psiquiátrica Intercontinental Hispanoamericana, asumiendo desde entonces multitud de cargos, tales como Director de publicaciones de la Sociedad Española de Psiquiatría (1967), miembro de la Junta Directiva de la Asociación Española de Neuropsiquiatría (1967), Presidente del Congreso de la Sociedad Española de Psiquiatría (1968), Presidente de la Sociedad Científica Española sobre Alcoholismo y Toxicomanías (1969), miembro de la Junta Rectora de la Ligas Española de Higiene Mental (1971), Presidente del XVIII Congreso Internacional de Alcoholismo y Toxicomanías (1972), Presidente del IX Congreso Internacional de Prevención y Tratamiento de Drogodependencias (1980), Presidente de la Sociedad Española de Psiquiatría y Psicología Sociales (1980), Presidente del IV Congreso Internacional de Psicomotricidad (1980), Presidente de la Sociedad Española de Psicopatología de la Expresión (1985), Presidente del Primer Congreso Internacional de la Asociación Europea de Psiquiatría y Psicopatología Sociales (1987), Miembro del Comité Ejecutivo de la Asociación Mundial de Psiquiatría Social (1989), Presidente de las X Jornadas Psiquiátrica del Hospital Necker (1991), o Presidente de la Asociación Europea de Psiquiatría Social (1998).

En los archivos de la Academia constan todos los reconocimientos que recibió. Aunque resulta imposible citar todos, destacamos no algunos de los que se sentía especialmente satisfecho, como eran Catedrático emérito vitalicio por la Universidad Complutense, los doctorados honoris causa por la Universidades de Montevideo, Fernando Pesoa de Oporto, Maimónides de Buenos Aires o Santo Domingo, Presidente de Honor de la Sociedad de Psiquiatría de América Latina, así como Miembro de Honor de multitud de Sociedades de Psiquiatría de Europa y Latinoamérica. Igualmente, siempre consideró una gran distinción y reconocimiento a su trayectoria la invitación a dictar en el Vaticano la conferencia "Inteligencia, Libertad y Santidad".

En cuanto a los premios y distinciones, que fueron multitud, estoy seguro de que él hubiera señalado ser Presidente de Honor de la Sociedad de Psiquiatría de América Latina, el Premio a la Excelencia Sanitaria por el Instituto Europeo de Salud y Bienestar Social, Asturiano del Año en 1981, el Premio Aula de Paz por la Universidad de Oviedo y la Medalla de Oro de Socidralcohol.

\section{El maestro y su escuela}

Que el profesor Alonso Fernández fue un maestro nadie lo duda. Un día hablando con él sobre el maestro me dijo que se identificaba con mis reflexiones sobre el maestro y el difícil reconocimiento de estos en un mundo actual invadido por los contravalores. Que duda cabe que de forma imperceptible nos vamos acostumbrando a la destrucción de lo bueno, tomando como norte a los que argumentan, sin más, que el mundo ha cambiado. Desde luego eso es así y sin entrar en otras cuestiones, tan solo en lo referente al binomio maestro-discípulo es una auténtica realidad. Y no es porque no haya maestros, que los hay, sino porque nadie quiere ser discípulo. Hoy se prefiere ser subordinado y así llamar jefe, a veces de forma peyorativa, al que otrora se le llamaría con todos los respetos maestro. No olvidemos que en otro tiempo pasado uno escogía al maestro y hoy se le asigna un jefe. A mi juicio, aquí está el problema y quizás un día debatamos en profundidad en esta Real Academia este asunto. 
Alonso Fernández lo tenía claro y sintonizábamos en este asunto. Él fue un gran maestro y tuvo la fortuna de disfrutar de multitud de discípulos, tanto directos como indirectos. La existencia de discípulos directos tiene un gran valor, pero estamos seguros de que lo tienen más los indirectos, pues ello quiere decir que, al margen de la dependencia y disciplina de grupo, los mensajes, pensamientos y propuestas calan a otros niveles y tienen sin duda alguna un recorrido mayor y más duradero.

En cualquier caso, son de recordar, como sin duda lo haría él, a todos los 62 doctorandos que dirigió sus tesis doctorales, así como a tantos discípulos españoles y latinoamericanos, y como no a sus hijas $M^{a}$ Dolores, Covadonga y Begoña, cada una dedicada a una rama del saber del maestro como la psicología, la psiquiatría y el psicoanálisis.

\section{El hombre. Un ejemplo de conducta}

Profunda huella dejó en Francisco Alonso Fernández, como hemos dicho anteriormente, el sufrimiento de su padre y la situación familiar durante y tras la guerra civil. Sin embargo, una vez pasados esos años abordó su vida, de forma absolutamente consciente, sin vivir en el resentimiento. Tras esos duros años se propuso que no dejaran en él "ningún trauma o patología mental", y que no condicionara su actitud de hombre libre a lo largo de su existencia. Tras la muerte de su padre en 1954 optó, por voluntad propia, por lo que denominó el "silencio político", como máxima expresión de la dignidad personal.

El profesor Alonso Fernández se distinguió siempre por su gran educación, amabilidad y afectuosidad. Exigente con él mismo, lo fue también en su compromiso con las diferentes responsabilidades que tuvo que afrontar en su vida. Pero por encima de ese carácter de exigencia por la excelencia, rezumaba una gran afabilidad y cercanía. En él destacaba su talante de hombre independiente que no mostraba rencor por nada ni por nadie. Para él la libertad era algo consustancial con el ser humano y cada uno desde ella interpretaba la vida.

Fue un hombre de profunda vocación social y humanística, dado a la amistad, la tolerancia y el respeto, tratando siempre de comprender las posiciones de todos. A lo largo de muchos años pude comprobar como sabía escuchar, ayudar, soportar, convivir y agradecer. Otra de sus fortalezas era no establecer competencias inútiles sino trabajar para construir y nada de perder el tiempo. Siempre digo que la vida, aunque nos parece demasiado corta, es lo suficientemente larga como para hacer muchas cosas. El profesor Alonso fue campeón en eso y en el reconocimiento mutuo, no siendo su estilo hablar mal de nadie.

Hombre competitivo en cuanto se proponía, lo fue también en sus aficiones, tal es el caso del tenis, que practicó hasta muy avanzada edad. Tal capacidad competitiva le llevó a participar en diversos torneos de los cuales se sentía muy orgulloso. Me recordaba con frecuencia que en 1989 jugó la final de veteranos entre el equipo del Club Puerta de Hierro y el Polo de Barcelona, ganando su partido individual

Para él la vida familiar lo fue todo. En el seno de la familia encontró la felicidad que compartió con Mary, su mujer y sus hijas y nietos. Mary, María Dolores San Martín con la cual se casó en 1950, el amor de su vida desde la juventud, fue el soporte esencial para poder alcanzar las metas que se propuso. Sentía un gran amor y admiración por ella y su ausencia fue una catástrofe en su vida. En este momento tan doloroso para todos, la recordamos junto a él, de la misma forma que a sus hijas María Dolores, Covadonga y Begoña, hijos políticos José Antonio y Jaime, así como sus nietos Violeta, Rebeca, Mateo, Manuel, Álvaro y Nastia, expresando nuestro más sincero pesar por su ausencia definitiva de la Real Academia.

Excmo Sr. Presidente, Excmos. Sras y Sres. Académicos, querida familia, señoras y señores, finalizo esta intervención agradeciendo de nuevo a la Junta Directiva mi designación para realizar este discurso necrológico en recuerdo del profesor Alonso Fernández, manifestando en nombre de esta Real Academia y en mío propio nuestro profundo pesar por la pérdida de tan insigne académico.

\section{DECLARACIÓN DE TRANSPARENCIA}

El autor/a de este artículo declara no tener ningún tipo de conflicto de intereses respecto a lo expuesto en el presente trabajo.
Si desea citar nuestro artículo:

Díaz-Rubio García M. Sesión necrológica en memoria del Prof. Francisco Alonso Fernández. An RANM. 2021;138(01).supl01: 40-46. D0I: 10.32440/ar.2021.138.01.supl01.art09 